\title{
Maupassant y lo fantástico ${ }^{*}$
}

Colette AsTIER

Université de Paris X-Nanterre

El punto de vista que desarrolla el presente texto plantea dos aspectos paradójicos. En efecto, de manera cuantitativa, la producción de cuentos fantásticos de Maupassant representa un conjunto menos importante que la producción clasificada dentro del realismo, con ascendentes conocidos: Flaubert como padre espiritual, y una relación, menos estrecha, aunque, sin embargo, obligada y generacional con Zola. De hecho, sólo se incluyen en esta vena unos quince textos breves, que contrastan con sus numerosísimos cuentos y sus extensas novelas. No obstante, lejos de presentarse como una excrecencia ocasional, este registro fantástico constituye una prolongación de toda la obra; mejor aún, representa una especie de transgresión de los límites y termina por revelar una visión global del mundo.

La segunda paradoja se refiera a la imagen que Maupassant ha dado de sí mismo: la de un vividor empedernido, a quien le gustan el canotaje y las mujeres. Sin embargo, al excluir asi, de manera frontal, el misterio y la duda, no se puede prescindir de regresar a ellos de manera indirecta, aun a expensas de que el misterio fácil se convierta en misterio de espanto. Efectivamente, hay algo ejemplar en la trayectoria y tal vez en la vida de Maupassant: las paradojas de este destino y de esta obra son capaces de operar una transmutación completa, digna de una fábula.

\section{La duda}

La literatura fantástica no se define solamente por lo extraño, lo fantasmagórico, la inquietud que produce, sino por su facultad de dudar y hacer dudar, por su indecisión erigida en sistema. El hecho fantástico ¿es verdadero? ¿Es falso?

"Texto leído en el "Homenaje a Maupassant", Facultad de Filosofia y Letras de la UNAM, el martes 16 de noviembre de 1993. 
¿Se trata de un fenómeno anormal o paranormal? ¿De una percepción $x$ ? ¿De la realidad explicable? De hecho, nunca se sabe dónde comienza lo sobrenatural y dónde termina lo natural - nunca se conoce la última palabra. A veces, incluso lo natural engloba lo sobrenatural y lo legitima, como en el caso de alucinaciones, de locura, etcétera.

Es preciso señalar, en efecto, la gran diferencia que existe entre lo maravilloso y lo fantástico. Lo maravilloso siempre se presenta como verdadero, aunque sea sólo en el tiempo de un cuento. Hay que creer en el Gato con Botas y en las hadas; lo fantástico, por el contrario, despierta e impone una interrogación. Los relatos fantásticos auténticos destilan una inquietud que su material (es decir, su temática de vampiros, de aparecidos, de tumbas entreabiertas) no alcanza a explicar: la angustia antecede a los accesorios del género.

En este terreno se sitúa Maupassant. Primero, porque existe una notable continuidad entre algunos de sus cuentos llamados realistas y aquellos denominados fantásticos. En "Velando a un muerto", un amigo de Schopenhauer asiste al cuerpo del filósofo, que parece reir; de pronto algo se mueve, cae intempestivamente de la cama para rodar debajo de un sillón. ¡Sorpresa! Angustia. En realidad, sólo se trata de la dentadura de Schopenhauer. Relato realista, tomado prestado de nuestro mundo racional $y$, sin embargo, rodeado por la escenografía de lo fantástico: el muerto, las velas, la situación llena de extrañas implicaciones, las cuales se resuelven fácilmente en este caso.

Pero lo extraño no siempre encuentra su resolución. Incluso la indecisión reviste a veces cualquier modulación posible, de lo más simple a lo más retorcido. Lo más sencillo se refiere al giro interrogante que presentan los títulos: “¿Él?”, “¿Un loco?”, “¿Loco?”, “¿Quién sabe?” Lo más perverso proviene de un desplazamiento de categorías, que confunde lo natural y lo sobrenatural, al punto de integrar lo sobrenatural al dominio de lo natural. "Sobre el agua" revela de manera inesperada, pero menos clara de lo que parece, el gusto personal de Maupassant por el canotaje. Un hombre que siente una gran pasión por los ríos se aventura en un paseo nocturno sobre el Sena, arroja el ancla. De pronto aparece la neblina. Malestar, ensoñación malsana. Para escapar a ello, el hombre intenta retirar el ancla y regresar. Imposible. Terror. El paisaje familiar se convierte en una visión, hasta llegar a ser la imagen de un paisaje improbable y poco realista, limitado por dos cortinas de neblina de ambos lados del Sena, mientras que éste se encuentra despejado. Al otro día un pescador llega a auxiliarlo; logran levantar el ancla: ésta había sido detenida por el cadáver de una anciana que llevaba una gran piedra atada al cuello. Por supuesto que la explicación es natural, racional, comprensible, pero ¿la visión fantástica y el terror que precedieron acaso no estaban ligados a alguna extraña - si no al menos sobrenatural- premonición de muerte? 
Es curiosa además la manera en que Maupassant deja a sus personajes teorizar sobre los lazos complejos de lo inexplicado y de lo explicable:

Cuando salgo por la noche - dice uno de ellos- ¡cómo quisiera estremecerme con la misma angustia que empuja a las ancianas a persignarse a lo largo de los muros de los cementerios y a escapar de los últimos supersticiosos frente a los extraños vapores de los pantanos (y de los fantásticos fuegos fatuos)! ¡Cómo quisiera creer en esa cosa vaga y terrorífica que uno imagina sentir al pasar por la oscuridad! [...] En realidad, sólo se siente verdadero miedo de aquello que no se comprende. ${ }^{1}$

Entonces se entiende la razón por la cual Maupassant permaneció tan apegado a una mano desollada que le había regalado Powell gracias al poeta Swinburne, y que más tarde sirvió de tema de inspiración para uno de sus cuentos. ${ }^{2}$ Lo importante reside en saber si los personajes y el autor junto con ellos no juegan al aprendiz de brujo y en qué términos.

\section{El miedo}

La respuesta es sencilla y al mismo tiempo constituye el segundo aspecto de este rápido recorrido: Jugar con el miedo da miedo. En efecto, al menos en la obra de Maupassant, todo cambio de perspectiva desemboca en un perpetuo descentramiento de lo exterior y de lo interior, que constituye el carácter específico de lo fantástico, que oscila entre el crujir de la superficie de la realidad y el resquebrajamiento de ésta, sin que sea posible situar su origen. Lo que se juega, participa entonces de una extraña dialéctica entre observar y ser observado, entre espíritu y mundo exterior. Un argumento de buena o tal vez de mala fe "¿quiẻn sabe?", puede encontrarse en "El miedo": "Qué es esto [el

${ }^{1}$ Guy de MAUPASSANT, "La peur", en Le Horla et otres contes crueles et fantastiques. Ed. de Marie-Claire Bancquart. Paris, Classiques Garnier, 1989, p. 207. "Quand je sors la nuit, come je voudrais frissonner de cette angoisse qui fait se signer des vieilles femmes le long des murs des cimetières et se sauver les derniers superstitieux devant les vapeurs étranges de marais. ¡Comme je voudrais croire à ce quelque chose de vague et de terrifiant que'on s'imaginait sentir passer dans l'ombre! [...] On n'a vraiment peur que ce qu'on en comprend pas".

${ }^{2}$ G. de MAUpassant, "La main d'échorché", en op. cit., p. 573. Sobre este episodio de la vida de Maupassant, véase René Dumenisl, Guy de Maupassant. París, Tallandier, 1947, p. 99, y Pierre-Georges Castex, Le conte fantastique en France. París, José Corti, 1951, p. 368. 
miedo común del peligro normal] en comparación con la convulsión que provoca al alma la idea de tropezarse con un espectro errante, sentir el abrazo de un muerto, ver a uno de esos monstruos espantosos que creó el terror de los hombres arrojarse sobre unos mismo?"3

Todo está dicho y una vez más la teoría propuesta por Maupassant es muy retorcida, porque no se trata del miedo a lo real sino del miedo a lo pensado y a lo imaginario - y por lo mismo de un círculo vicioso. Es preciso insistir: del miedo a esos monstruos horribles que inventó el terror de los hombres. El terror inventa temas de terror al miedo, creando un circuito cerrado de donde resulta imposible escapar. Ya no existe solución de continuidad entre el interior y el exterior, entre lo pensado y lo vivido. La mueca de lo real y la de la interioridad acaban por confundirse. Un cuento muy conocido, que no tiene nada de fantástico: “¡Camarero, un tarro!”, revela este mismo mecanismo. Es la historia de un muerto en vida que desperdicia su existencia en una taberna y divide su tiempo entre repetir esta orden ( $i$ Camarero, un tarro!) y dormir por las mañanas. No invoca ninguna desdicha que justifique esta actitud, pero termina por confesar que a los trece años presenció una escena de violencia entre sus padres. Después de este descubrimiento, sólo tuvo ojos para lo que él llamaba "el lado malo de las cosas". La mirada que alguna vez aisló lo peor quedó clavada en lo peor, $y$ sólo capta del mundo lo peor.

La obra de Maupassant abunda en personajes que empobrecen su campo de visión en esta forma, a causa de una sensibilidad excesiva. La "Reina Hortensia", solterona empedernida y amargada, sólo da muestras de ternura reprimida en el delirio de su agonía. ${ }^{4}$ Pero lo más interesante no es tanto este movimiento de la percepción que se vuelca entre el idilio y el horror, sino la lección que nos da: la cualidad de lo percibido está relacionada con la naturaleza de la mirada que lo percibe y todo lo fantástico de Maupassant se inscribe en esta consideración del otro lado de las cosas. Lo fantástico se establece, de manera privilegiada, sobre los espacios en donde puede ejercerse cierta aptitud para percibir el horror del mundo tal como es. Cualquier mirada, incluso cualquier neurosis, halla lo que busca en la diversidad de lo real —el delirio de persecución encuentra indefectiblemente la palabra que hiere o la agresividad de la cual se nutrirá; la depresión, la tristeza que justifica su pesimismo, etcétera.

${ }^{3}$ G. de MAUPASSANT, "La peur", en op. cit., p. 207. "Quést cela auprès de la convulsion que donne à l'âme la pensée qu'on va rencontrer un spectre errant, qu'on va subir l'étreinte d'un mort, qu'on va voir accourir une de ces bêtes effroyables qu'inventa l'épouvante des hommes?"

${ }^{4}$ G. de MAUPASSANT, "La reine Hortense", en op. cit., p. 73. "Elle rêve qu'elle a des enfants et un mari, c'est l'agonie qui commence". 
Una vez más, el delirio y la locura en la óptica de Maupassant son mucho más ambiguos de lo que parecen: no basta decir que estos personajes son locos para liberarse de sus alucinaciones y relegarlas en la importuna fantasmagoría. Esta ambigüedad, que se traduce a través de los signos de interrogación de los títulos (“¿Loco?”, “¿Un loco?”, “QQuién sabe?”) también explica que todos esos delirios no sean completamente falsos, sino a menudo razonadores, lúcidos y lógicos. La cuestión de la locura se debate al exterior de los cuentos. " $\mathrm{Si}$ no estuviera seguro de lo que vi, seguro de que no hubo en mis razonamientos ninguna flaqueza, ningún error en mis constataciones, la menor laguna en la inflexible sucesión de mis observaciones, me creería un simple alucinado, juguete de una extraña visión. Después de todo ¿quién sabe?"5

El cuento se llama precisamente "¿Quién sabe?" Todos opinan sobre el caso del narrador, de pronto vacilan y nosotros quedamos embarcados - al mismo tiempo involucrados - en sus vacilaciones. "Dígame, ¿estoy loco?", interroga al final del cuento. “Loco?”, el protagonista que se preguntaba al inicio: "Soy loco o únicamente celoso?"7 En "El horla", ¿se trata de una simple alucinación?

Entre los personajes de estos tres cuentos, la desviación respecto a lo que se considera como la norma, no es tan grande para que no tenga un poco de razón. El primero ha visto salir de su casa sus muebles, el segundo ha sido devorado por los celos al grado de matar (estaba celoso de un caballo); el tercero tiene problemas de identidad. La locura de Hamlet, sobre otro registro, posee también su orden de cordura. Por la indecisión fantástica - cabe señalarlo-, la locura sólo da la impresión de ser una calca (absurdo contra absurdo y horror contra horror) de la locura del mundo. Por desquiciada que sea, no está del todo equivocada. Por esta razón, se encuentran en los cuentos de Maupassant tantos personajes que van al auxilio de los locos y buscan comprobar la veracidad de sus visiones. El personaje de “¿Quién sabe?”, víctima o no de una alucinación, efectivamente ya no tiene sus muebles y su sirviente lo atestigua. Aunque pareciera imposible, la policía encuentra la huella del diabólico anticuario, en cuya casa aparecen estos mismos muebles. Al otro día por la mañana, los muebles han abandonado completamente la casa del anticuario y la policía da fe de este acto. Se encuentran de nuevo en el castillo y el sirviente que había constatado su partida, así como la policía, dan fe una vez

${ }^{5}$ G. de MAUPASSANT, “Qui sait?", en op. cit., p. 511 . "Si je n'étais sûr de ce que j'ai vu, sûr qu'il n'y a eu dans mes raisonnements aucune défaillance, aucune erreur dans mes constatations, pas de lacune dans la suite inflexible de mes observations, je me croirais un simple halluciné, le jouet d'une étrange vision. Après tout, qui sait?"

'G. de MAUPASSANT, "Fou?", en op, cit., p. 23. "Dites-moi, suis-je fou?"

${ }^{7}$ Ibid., p. 19. "Suis-je fou? ou seulement jaloux?" 
más del hecho, de modo que las visiones son comprobadas por testigos neutros a priori y corroboradas por el relato. Queda comprobada la veracidad que contiene la locura.

Pero la "maquinaria" de estos textos, al ser tan complicada, obliga a Maupassant a recordar los tópicos del género. El anticuario de "¿Quién sabe?" está relacionado con una mujer que el autor representa como "una especie de bruja"; las notaciones extrañas abundan: el almacén del anticuario, por ejemplo, es un lugar fantástico en el sentido común de la palabra. Además, las pistas se enredan porque - para parafrasear a Pascal, que hablaba del corazón- la locura tiene su razón que la razón desconoce.

El contagio de la locura hace de ésta un asunto común, un asunto compartido. El cuento intitulado "La cabellera" se refiere a un tema de moda según las leyes del género fantástico: la necrofilia -después de todo Maupassant era lector de Edgar Allan Poe. El protagonista, enamorado de una trenza que encontró en los cajones de un antiguo escritorio, habla como un "Poseído" —con mayúscula, es el texto el que habla - y se siente invadido por una irresistible emoción cuando el médico le arroja la cabellera desde el otro lado de su consultorio. "Me estremeci al sentir sobre mis manos su tacto acariciador y ligero, y permanecí con el corazón palpitando de asco y de deseo. De asco, como al contacto de objetos arrastrados en los crímenes. De deseo, como frente a la tentación de algo infame y misterioso".

Contagio entonces de deseo necrofilico, que es loco y que no lo es, y permite así que esta locura se expanda. Sin embargo, es necesario llegar hasta la última frase para entender el sentido profundo del cuento, al escuchar el fallo del médico, del clínico: "La mente del hombre es capaz de todo”. ${ }^{9}$ ¡Por supuesto!, y esto convierte el texto en un cuento antropológico, el de la locura generalizable y comprensible -si no generadora. Una locura a la imagen del mundo y a la imagen de cada uno de nosotros. Una vez más interior y exterior se equiparan.

Esto explica por qué Maupassant se siente tan atraído por las incursiones del lado de la patología. "Los locos me atraen", reconoce en "Madame Hermet": "[...] Esta gente vive en un país misterioso de sueños extraños, dentro de esa nube impenetrable de la demencia donde todo lo que han visto sobre la tierra, todo lo que han amado, todo lo que han hecho recomienza en una existencia

${ }^{8}$ G. de MAUPASSANT, "La chevelure", en op. cit., p. 188. "Je frémis en sentant sur mes mains son toucher caressant et léger. Et je restai le coeur battant de dégoût et d'envie, de dégoût comme aụ contact des objets traînés dans les crimes, d'envie comme devant la tentation d'une chose infâme et mystérieuse".

${ }^{9}$ Ibid., p. 188. "L'esprit de l'homme est capable de tout". 
imaginada fuera de todas la leyes que gobiernan las cosas y rigen el pensamiento humano". ${ }^{10}$

Los locos exponen su interioridad al exterior -esta misma interioridad que ha sido quebrantada por el exterior-y ya no se sabe por dónde ha comenzado el mal en este juego de descentramientos sucesivos. Así es como la interioridad se llena.

El cuento que se intitula "¿Un loco?" presenta a un magnetizador asustado por su propio poder. El cuento se constituye, de cabo a rabo, como un intercambio continuo entre lo natural y el misterio, mediante lo que en esa época llamaban "magnetismo". De su relación con los médicos, de sus encuentros con Charcot, Maupassant sólo retuvo una idea: el magnetismo actúa $\longrightarrow$ actuaría - a la manera de un embrujo capaz de desplazar los objetos, pero sobre todo de revelar los secretos del corazón. "iQué ser tan singular, tan perturbador, que anunciaba, que arrojaba un malestar alrededor de sí, un vago malestar del alma, del cuerpo, uno de esos nerviosismos incomprensibles que hacen creer en influencias sobrenaturales!" II

El cuento va a establecerse como un lazo entre lo natural y lo sobrenatural, un lugar de descentramiento en el cual hombres, animales y objetos (como por casualidad, el objeto privilegiado es a pesar de todo un cuchillo) no hacen o no son lo que se esperaba. El fondo del alma también - Charcot lo garantizapuede dejarse ocultar. Vale la pena recalcar lo que el cuento dice del alma: "Él [el magnetizador] le roba el pensamiento, es decir su alma, el alma, este santuario, este secreto del yo, el alma, este fondo del hombre que se creía impenetrable, el alma, este asilo de las ideas inconfesables, de todo lo que se esconde, de todo lo que se ama, de todo lo que se quiere encubrir a todos lo humanos, jél la abre, la viola, la expone, la arroja al público!"12

Dos ideas trascienden en estas líneas: el descentramiento, pero también la profundidad insondable, insondable y abyecta del yo. Una vez más, la locura y lo real se encuentran, se hacen eco y se transmiten uno al otro su propia pertur-

10 G. de Maupassant, "Madame Hermet", en op. cit., p. 451. "Les fous m'attirent. Ces gens-là vivent dans un pays mystérieux de songes bizarres, dans ce nuage impénétrable de la démence où tout ce qu'ils ont vu sur terre, tout ce qu'ils ont aimé, tout ce qu'ils ont fait recommence pour eux dans une existence imaginée en dehors de toutes les lois qui gouvernent les choses et régissent la pensée humaine".

$"$ G. de MAUPASSANT, "Un fou?", en op. cit., p. 219. "Quel être singulier, troublant, qui apportait, qui jetait un malaise autour de lui, un malaise vague, de l'âme, du corps, un de ces énervements incompréhensibles qui font croire à des influences surnaturelles!"

${ }^{12} \mathrm{Ibid}$., p. 221. "Il lui vole sa pensée, c'est-à-dire son âme, l'âme, ce sanctuaire, ce secret de Moi, l'âme, ce fond de l'homme qu'on croyait impénétrable, l'âme, cet asile des inavouables idées, de toute ce qu'on cache, de tout ce qu'on aime, de tout ce qu'on veut celer à tous les humains, il l'ouvre, la viole, l'étale, la jette au public!" 
bación. La pasión que es loca es insondable pero está, en los hechos, dictada por el mundo, cuyo misterio también es insondable y loco. Es un juego de espejos.

He aquí por qué estos cuentos de la locura rebasan, y con mucho, los límites, los códigos y las prescripciones patentadas del género; porque no se reducen a la fascinación del escritor para estos estados paranormales y para su propia experiencia patológica. Su interés por la enfermedad mental, que además se manifestó muy temprano, corresponde a una visión, y lo que se libera (más allá de las necesidades estructurales de la maquinaria de los cuentos y más allá de los riesgos personales) es la convicción, desde mucho tiempo arraigada en él, de que el mundo es en verdad como los locos lo piensan. Recordemos los versos de Macbeth: "El mundo es un cuento lleno de ruido y de furor contado por un idiota".

Toca entonces hablar de ese ruido y de ese furor propios de Maupassant.

\section{Lo peor es siempre lo cierto}

La perfecta continuidad de la obra de Maupassant consiste en que lo fantástico aparece como una expresión de la visión del mundo, en donde lo peor es siempre lo cierto. Lo fantástico rebasa los límites de la caricatura, llevada hasta lo insoportable, lo intolerable, y lo "inadministrable", aspectos ligados uno al otro porque todos transgreden los límites. Por ejemplo, en la novela Fuerte como la muerte (novela psicológica, novela de amor cuyo título cita al Cantar de los cantares, pero para pervertirlo), la enamorada Madame de Guilleroy vela a su amante Olivier Bertini mientras él agoniza. Olivier le ordena quemar su correspondencia, y ella obedece. "[... En el brasero] ella vio fluir algo rojo, podría decirse que eran gotas de sangre. Parecían salir del interior de las cartas, como de una herida y se deslizaban suavemente hacia las llamas dejando una estela purpurina". ${ }^{13}$

Pero en una novela realista, la visión sobrenatural se reduce a lo banal: "[...] Después ella comprendió, de golpe comprendió que lo que acababa de presenciar era simplemente la cera de los sellos que se había derretido". ${ }^{14}$

${ }^{13}$ Fort comme la mort. París, Le livre de Poche, 1965, p. 246. “[...] sur l'amas de papiers à moitié consumés déjà, qui se tordaient et devenaient noirs, elle vit couler quelque chose de rouge. On eût dit des gouttes de sang. Elles semblaient sortir du coeur même des lettres, comme d'une blessure, et elles glissaient doucement vers la flamme en laissant une traînée de pourpre".

${ }^{14}$ Idem. "La comtesse reçut dans l'âme le choc d'un effroi surnaturel et elle recula comme si elle eût regardé assassiner quelqu'un, puis elle comprit, elle comprit tout-àcoup qu'elle venait de voir simplement la cire des cachets qui fondait". 
Sin embargo, esta mujer sólo llora la pérdida de su confort, que había confundido como su felicidad. De hecho, lo fantástico resalta el dolor y la pasión; se da como un refinamiento de la visión de lo peor que permite, en cierta forma, llegar a lo absoluto sin recurrir al sentimentalismo ni a la filosofía. Lo fantástico permite señalar el chillido del dolor sin caer en la grandilocuencia, y es así como esta obra escrita de manera tan escueta, casi seca, clama su intolerancia al mal. Su victorioso clasicismo enuncia su angustia; su agudeza expresa su impotencia para soportar, como el protagonista de " $i$ Camarero, un tarro!", que el orden del mundo esté alejado de lo idílico.

Lo fantástico implica (y por eso era necesario recordar la oposición entre fantástico y maravilloso) el descubrimiento de la fractura irremediable que existe dentro del mundo real, explicable, dominado y dominable. También es la revelación de que cuando esta superficie se resquebraja, la persona también se fisura. El hombre y la vida se descomponen y, por esta razón, estos cuentos fantásticos parecen el remate de una obra tan desconsolada, la puesta en evidencia de una situación irreversible.

\section{La angustia}

La obra de Maupassant, ligada a una experiencia de la angustia, no es solamente un juego con la angustia como en Gautier, en Mérimée y algunas veces como en Poe, sino expresión directa de esta angustia. Al hacer independiente de la patología propia a Maupassant la redacción de esta parte de su obra, nunca se puede afirmar desde afuera qué es lo que alimenta la creación, aunque es segura su familiaridad con la angustia, comprobada además por las memorias de su sirviente François Tassart. "[...] Se siente el miedo vago de lo invisible, el miedo de lo desconocido que está detrás del muro, detrás de la puerta, detrás de la vida aparente. Con él [el gran novelista ruso Turgueniev], somos bruscamente atravesados por luces sospechosas que sólo iluminan lo suficiente para aumentar nuestra angustia". ${ }^{15}$

$Y$ este terror que tenía su origen fuera de nosotros y en nosotros, encuentra su consagración en la pintura de las crisis de soledad. Como en el Génesis, en Maupassant no es recomendable que el hombre permanezca solo.

${ }^{15}$ G. de Maupassant, "La peur", en op. cit., pp. 207-208. "Avec lui [Turgueniev], on la sent bien, la peur vague de l'Invisible, la peur de l'inconnu qui est derrière le mur, derrière la porte, derrière la vie apparente. Avec lui, nous sommes brusquement traversés par les lumières douteuses qui éclairent seulement assez pour augmenter notre angoisse". 


\section{El miedo a si mismo}

¿Por qué, si no es porque el hombre solo se enfrenta a su profunda inseguridad? Se encuentra con la parte de lo irremediable que lleva consigo. Porque es en él en donde halla su origen la inquietante extrañeza de la que hablaba Freud. Así lo muestra el argumento (en realidad tan conmovedor a pesar de la risa socarrona) del cuento intitulado “ $¿$ Él?” Un ser dispuesto a casarse con cualquiera para no quedarse solo, no quiere quedarse solo por miedo a reencontrarse con su doble.

No tengo miedo a un peligro, a cualquier hombre que entrara lo mataría sin estremecerme, no tengo miedo de los aparecidos [...] creo en el aniquilamiento definitivo de cada ser que desaparece. [...] iEntonces!... ¡Pues bien! Tengo miedo de mí, miedo del miedo, miedo de los espasmos de mi espíritu que se aterra, miedo de esta horrible sensación de terror incomprensible. Esto es espantoso, incurable [...] Tengo miedo sobre todo de una perturbación horrible de mi pensamiento, de mi razón que se me escapa enredada, dispersada por una misteriosa e invisible angustia. Al principio siento una vaga inquietud que pasa por mi alma y hace correr un escalofrío por mi piel [...] tengo miedo únicamente porque no comprendo mi miedo [...] me agito, siento aumentar mi espanto; y me encierro en mi habitación; y me meto en la cama, y me escondo bajo las sábanas; y acurrucado en forma de ovillo, cierro los ojos desesperadamente... ${ }^{16}$

Este miedo a la soledad es el miedo a descubrirse en la soledad. Porque en Maupassant yo es abominablemente otro. El argumento de "El horla" introduce por ello el tema de la pérdida de identidad. Es el tema, en el sentido estricto, d'être mal dans sa peau, de "estar mal en su pellejo", según la expresión fami-

${ }^{16}$ G. de MAUPASSANT, “Lui?", en op. cit., p. 88. "Je n'ai pas peur d'un danger. Un homme entrerait, je le tuerais sans frissonner. Je n'ai pa peur des revenants; je ne crois pas au surnaturel. Je n'ai pas peur des morts; je crois à l'anéantissement définitif de chaque être qui disparaît. Alors!... oui. Alors!... Eh bien! j'ai peur de moi! j'ai peur de la peur; peur des spasmes de mon esprit qui s'affole, peur de cette horrible sensation de la terreur incompréhensible. [...] Cela est affreux, inguérissable. [...] J'ai peur surtout du trouble horrible de ma pensée, de ma raison qui m'échappe brouillée, dispersée par une mystérieuse et invisible angoisse. Je sens d'abord une vague inquiétude qui me passe dans l'âme et me fait courir un frisson sur la peau [...] j'ai peur uniquement parce que je en comprends pas ma peur. [...] Je m'agite, je sens mon effarement grandir; et je m'enferme dans ma chambre; et je m'enfonce dans mon lit, et je me cache sous mes draps; et blotti, roulé comme une boule, je ferme les yeux désespérément..." 
liar. Se puede fantasear un poco con la palabra "Horla": "Hors de là" (fuera de allá) -"Hors d'ici" (fuera de aquí) - "Hors de chez soi" (fuera de su casa, fuera de sí). Fuera del narrador que se excluye de sí mismo, de su casa, incluso de toda la gente de casa. Al grado de olvidar a sus sirvientes, de olvidar pedirles auxilio y por último olvidar apartarlos del incendio que provocó. Fuera de sí, fuera de su cabeza, fuera de su corazón.

Lo fantástico, definido como género literario, permite la reducción que despoja de sí y permite llegar al meollo de la obra, a través de una vía en apariencia tan estrecha. Estos textos solamente intensifican la visión que el resto de la obra no dejaba de proponer.

Estos cuentos, que dibujan el arabesco del terror, son tal vez menos fantásticos de lo que parecen: sólo realizan un inventario del sufrimiento del mundo. Maupassant escribió alguna vez a Flaubert: "A ratos percibo tan nítidamente la inutilidad de todo, la maldad inconsciente de la creación; el vacío del porvenir (cualquiera que éste sea) que me siento invadido por una triste indiferencia hacia todas las cosas. ${ }^{17}$ [...] Veo cosas cómicas, cómicas, cómicas y otras tristes, tristes, tristes; en suma todo el mundo es tonto, tonto, tonto aquí como en cualquier parte". ${ }^{18}$

Este propósito encontrará su mitología en el personaje de Moiron que, al asesinar a los niños, quiere competir en maldad con Dios. "Comprend'́ que Dios es malo. ¿Porqué había matado a mis hijos? Abrí los ojos y entendí que le gusta matar, que sólo le gusta esto [...] Dios, Señor, es un asesino [...] un canalla". ${ }^{19}$

Este alegre vividor que era Maupassant, ¿acaso no quiso también crear la figura novelesca del hombre pascaliano, prendado de diversiones para escapar a la miseria del Hombre sin Dios?

\section{Traducción de Claudia Ruiz}

${ }^{17}$ Carta de Maupassant a Flaubert, 5 de julio de 1878, citada por Pierre-Georges Castex, en op. cit., p. 367: "Il me vient par moments des perceptions si nettes de l'inutilité de tout, de la méchanceté inconsciente de la création, du vide de l'avenir [quel qu'il soit], que je me sens venir une indifférence triste pour toutes choses".

${ }^{18}$ Carta de Maupassant a Flaubert, 26 de diciembre de 1879, ibid., p. 367: "Je vois des choses farces, farces, farces, et d'autres tristes, tristes, tristes; en somme tout le monde est bête, bête, bête, ici comme ailleurs".

${ }^{19}$ G. de Maupassant, "Moiron", en op. cit., pp. 478-479. "Je compris que Dieu est méchant. Pourquoi avait-il tué mes enfants? J'ouvris les yeux, et je vis qu'il aime tuer. Il n'aime que ça, Monsieur. Il en fait vivre que pour détruire! Dieu, Monsieur, c'est un massacreur. Il lui faut tous les jours des morts. [...] Canaille, va!" 